\title{
Hypothesis behavior in a multidimensional oddity problem'
}

DANIEL S. LORDAHL

UNIVERSITY OF MIAMI

\begin{abstract}
Abstraet
Three groups of college students attempted to solve an oddity problem in which stimuli were varied along five bi-leveled dimensions. Knowledge of results was given only when a $\mathrm{S}$ was correct on all three trials of a block of trials. The group receiving "oddity" instructions gave significantly higher proportions of response sequences which fit the assumed use of an oddity hypothesis than did the other two instruction groups.

\section{Problem}

Levine $(1959,1963)$ has approached the study of hypothesis behavior by using a model which permits simultaneous estimation of the relative use of a variety of hypotheses or tendencies. This approach seems efficient in general and in specific permits analysis of incorrect hypotheses which Ss may employ in problem solving situations. However, unless the proposed set of hypotheses is quite complete, the estimates of each hypothesis may be partially correlated or confounded with unknown strategies based upon the features of the stimuli. The oddity problem has the advantage that, over a series of trials, the correct stimulus changes characteristics. For instance, in a set containing two blue and one red object (with color relevant) the red object is correct, but the blue object is correct if two red objects are present.

The present study is an attempt to explore the usefulness of the oddity-type problem for the estimation of of hypothesis behavior in humans.
\end{abstract}

\section{Method}

Stimuli and Task.On any given trial, $\mathrm{S}$ was presented with three sets of geometric designs (Fig. 1) and was required to pull one of three levers corresponding to his choice of one of the patterns. Stimulus patterns varied along five bi-leveled dimensions: number (two or three), shading (open or filled), location (top or bottom of screen), dot (presence or absence of a dot above the forms), and slope (forms arranged with positive or negative slope). Trials were broken into blocks of three, and stimuli for the single sequence used were selected randomly with the following restrictions: (a) each trial contained an odd pattern with respect to each dimension, and (b) no two dimensions yielded the same sequence of oddity patterns within a block of three trials.

Stimuli were presented for Ss' viewing by rear projection from a $16 \mathrm{~mm}$ filmstrip projector onto a translucent paper screen mounted in a partition. Responses were self paced and stimuli remained in view for 2 sec. following Ss' responses. A blank frame followed each block of three trials. Ss were reinforced by the

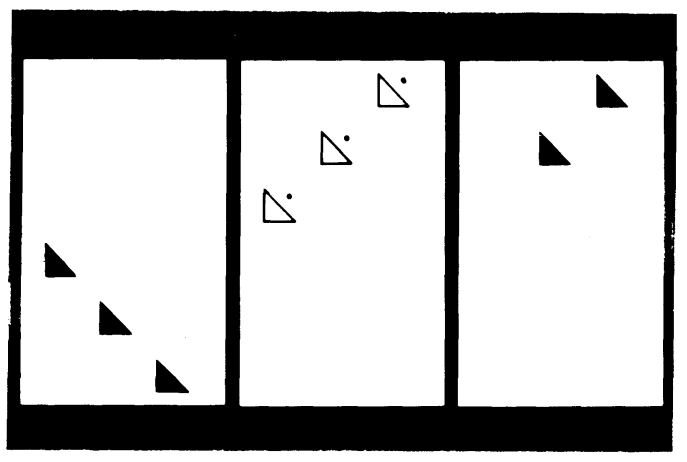

Fig. 1. An example of a set of stimuli for a given trial

spoken word "correct" only when all trials of the preceding block were correct, i.e., appropriate to the selected problem condition.

Treatments. Five oddity problems were combined with three instruction conditions in a factorial design. Three different Ss were randomly assigned to each of the resultant 15 treatments. All Ss were instructed as to the procedures to be followed, including the feedback relationships, and were told to discover the rule of the problem which would allow their complete accuracy on all trials. The control instructions (Group C) included no further information about the type of rule to be used. Instructions for Group $\mathbf{R}$ informed the Ss that the appropriate rule did not involve any type of response sequence and that viewing the stimuli presented was required for solution. Group O Ss were told that the problem was an oddity problem, that only one aspect of the stimuli would be relevant, and were given a verbal example of an oddity problem using oranges and apples.

Each of the dimensions of stimulus variation was used as relevant to give the five problem conditions.

All Ss were given 28 blocks of trials unless a criterion of four successive blocks of correct trials was satisfied.

\section{Results and Diseussion}

Number of solvers and mean trials to solution (or end of session) were, respectively, 5 and 20.5 for Group C, 7 and 20.0 for Group R, and 7 and 18.0 for Group O. Differences in mean trials to criterion were not reliable for instructions, problems, or the interaction when tested with analysis of variance.

Out of the 27 possible response sequences for each block of trials, five sequences correspond to the five possible oddity hypotheses. Each $\mathrm{S}$ was scored in terms of the proportion of his presolution trials (including the 
TABLE I

Mean Proportions of Oddity Responses

\begin{tabular}{|c|c|c|c|c|c|c|}
\hline \multirow[t]{2}{*}{ Group } & \multicolumn{6}{|c|}{ Dimension Tested } \\
\hline & Shade & Number & Location & Dot & Slope & Total \\
\hline$C$ & .11 & .09 & .08 & .10 & .05 & .42 \\
\hline $\mathrm{R}$ & .06 & .11 & .05 & .11 & .06 & .39 \\
\hline 0 & .21 & .26 & .02 & .09 & .10 & .68 \\
\hline Average & .13 & .15 & .05 & .10 & .07 & \\
\hline
\end{tabular}

first block of the criterion run) which corresponded to each oddity sequence. Table 1 displays the mean proportions obtained by instruction group and oddity sequence (dimension tested). An analysis of variance on these scores revealed significant difference due to instructions $(p<.001)$ and dimensions tested $(p<.001)$ as well as the significance of the interaction of these terms suggested in Table $1(p<.01)$. Clearly, a higher degree of oddity type response sequences is shown under oddity instructions. Moreover, this tendency seems to be greatest for the shading and number dimensions. The variable of problems was not significant as a main effect but did interact with instructions $(p<.01)$ and dimensions $(p<.05)$. These terms seem to reflect a strong tendency for Ss in Group $O$ to give very high scores for shading and number when these were relevant dimensions, and a slight tendency for all groups to give higher scores on the dimension which was relevant. This finding may be interpreted as being caused by the inclusion of the first block of the criterion run and by the small tendency of some Ss to make an error after presumably discovering the solution.
In order to obtain a rough estimate of the actual proportions of oddity hypotheses entertained by Ss, the total number of oddity response sequences was subdivided on the basis of whether or not the corresponding dimension remained at the same level on all three trials of the block. When this condition did obtain (call it LS), it may be that the $S$ was responding to a particular aspect of the stimuli per se rather than to oddity. The other total (LD), when corrected for chance, should give a better estimate of the proportion of oddity hypotheses. The resulting totals (excluding the criterion run) with LD given first were: Group C, 57-33; Group R, 48-39; and Group O, 106-39. These are based on total trial blocks of 308,298 , and 259, respectively. If all of the LS total were spurious and are subtracted from the total trial blocks, the application of the chance factor of 5/27 virtually eliminates all "true" oddity hypotheses from Groups $\mathrm{C}$ and $\mathrm{R}$ while still yielding about $30 \%$ oddity hypotheses in Group O. While these estimates are admittedly gross, they do seem to support the contention that the oddity principle was tried much more often under oddity instructions.

Both the oddity problem and the method of analysis, with refinements, seem well suited to the analysis of hypothesis behavior in humans.

\section{References}

Levine, M. A model of hypothesis behavior in discrimination learning set. Psychol. Rev., 1960, 67, 207-223.

Levine, M. Mediating processes in humans at the outset of discrimination learning. Psychol. Rev., 1963, 70, 254-277.

\section{Note}

1. This research was supported by Grant MH 10277 from the National Institute of Mental Health.

\section{Comment on Burstein by J. W. Moore}

Recent reports by Burstein (1965) and Spence \& Platt (1965) point up one area where cross-laboratory comparisons of results from human eyelid conditioning can be facilitated. This is in specification of the intensity of an airpuff UCS. Some laboratories customarily measure static air pressure in psi; others prefer measurement with the more sensitive mercury (Hg) manometer. The conversion from psi to $\mathrm{mm} \mathrm{Hg}$ is $760 \mathrm{~mm} \mathrm{Hg}=14.696 \mathrm{psi}$, i. e., 1 psi of pressure equals approximately $51 \mathrm{~mm} \mathrm{Hg}$ in a 1/4 in manometer. We suggest that, as a courtesy, investigators use the conversion formula and specify UCS intensity both ways.

\section{References}

Burstein, K. R. The influence of UCS upon the acquisition of the conditioned eyelid response. Psychon. Sci., 1965, 2, 303-304。

Spence, K. W。 \& Platt, J. R。 UCS intensity and performance in eyelid conditioning. Technical Report No. 2, Nonr 375 (19), 1965. 